\title{
Tonal Patterns and Extrametricality of Japanese 2-Pattern Accent Systems*
}

\author{
Sunghye Cho \\ University of Pennsylvania
}

\section{Introduction}

This paper aims at providing a formal analysis of the tonal patterns of four Japanese dialects with $n$ pattern accent systems. Most of the dialects with $n$-pattern systems are spoken in the Southwestern part of Kyushu. These dialects share many characteristics but still show interesting differences in their tonal patterns. In the following sections, I briefly explain the classification of Japanese accent systems (1.1 \& 1.2) and how previous studies approach these $n$-pattern dialects ( $2.1 \& 2.2)$. In Section 3, I introduce this paper's main proposal, and in Section 4, I provide a new way of approaching two 2-pattern dialects, Kagoshima and Koshikijima Japanese, without assuming underlying tonal melodies. In Section 5, I extend my analysis to other 2-pattern dialects, and in the final section, I summarize the advantages of the present approach.

1.1 Japanese accent system According to Uwano (1999, 2012), Japanese dialects are divided into two major groups: accentless and accented. Accentless dialects do not show a consistent tonal pattern, and they are not of interest in this paper. Accented dialects can be further classified into multi-pattern and $n$-pattern systems. In multi-pattern systems, more tonal patterns are observed as the length of a word increases. For example, in Tokyo Japanese, the number of tonal patterns that can be observed in a word with $n$ number of TBUs (Tone Bearing Units), is $n+1$. Consider the following examples: ${ }^{1}$

(1) Tonal patterns of Tokyo Japanese (Kubozono, 2012)

$\begin{array}{lll}\text { Monosyllabic nouns } & \text { HI-ga } & \begin{array}{l}\text { 'fire-NOM' } \\ \text { 'sunshine-NOM }\end{array} \\ \text { Disyllabic nouns } & \text { HA.si-ga } & \text { 'chopstick-NOM' } \\ & \text { ha.SI-ga } & \text { 'bridge-NOM' } \\ & \text { ha.SI-GA } & \text { 'end-NOM' } \\ \text { Trisyllabic nouns } & \text { I.no.ti-ga } & \text { 'life-NOM' } \\ & \text { ko.KO.ro-ga } & \text { 'heart-NOM' } \\ & \text { o.TO.KO-ga } & \text { 'man-NOM' } \\ & \text { sa.KA.NA-GA } & \text { 'fish-NOM' }\end{array}$

As the examples clearly show, the number of the observed tonal patterns increases when more TBUs are added. Monomoraic nouns have two possible tonal patterns, bimoraic nouns have three patterns, and trimoraic nouns have four possible patterns.

1.2 n-pattern system Contrary to multi-pattern systems, dialects with an $n$-pattern system have only $n$ number of tonal patterns, regardless of the length of a word. The field identifies 1-pattern, 2-pattern, and

\footnotetext{
* I would like to thank Eugene Buckley and Rolf Noyer for their advising and valuable comments. I am grateful for the feedback provided by audiences at the Annual Meetings on Phonology 2014. I also want to thank Jeroen Breteler, who shared his thesis and other papers on Japanese $n$-pattern dialects and gave helpful comments on the current work. Any errors remain my own.

1 Throughout the entire paper, capital letters are used for H-toned TBUs, and lowercase letters are used for L-toned TBUs. Syllable boundaries are marked with a period, and morphological boundaries are marked with a hyphen.
} 
3-pattern systems, and the majority of these dialects have a 2-pattern system. The following shows examples of Kagoshima and Koshikijima Japanese, which have two tonal patterns (Type A and Type B).

(2) Tonal patterns of Kagoshima Japanese

\begin{tabular}{|c|c|c|c|c|}
\hline Number of TBU & 2 & 3 & 4 & 5 \\
\hline \multirow[t]{3}{*}{ Type A } & $\begin{array}{l}\text { A.me } \\
\text { 'candy' }\end{array}$ & $\begin{array}{l}\text { sa.KA.na } \\
\text { 'fish' }\end{array}$ & $\begin{array}{l}\text { ke.da.MO.no } \\
\text { 'wild animal' }\end{array}$ & $\begin{array}{l}\text { na.tu.ya.SU.mi } \\
\text { 'summer break' }\end{array}$ \\
\hline & & $\begin{array}{l}\text { a.ME-ga } \\
\text { 'candy-NOM' }\end{array}$ & $\begin{array}{l}\text { sa.ka.NA-ga } \\
\text { 'fish-NOM' }\end{array}$ & $\begin{array}{l}\text { ke.da.mo.NO-ga } \\
\text { 'wild animal-NOM' }\end{array}$ \\
\hline & & & $\begin{array}{l}\text { a.me-KA.ra } \\
\text { 'candy-from' }\end{array}$ & $\begin{array}{l}\text { sa.ka.na-KA.ra } \\
\text { 'fish-from' }\end{array}$ \\
\hline \multirow[t]{3}{*}{ Type B } & $\begin{array}{l}\text { a.ME } \\
\text { 'rain' }\end{array}$ & $\begin{array}{l}\text { i.no.TI } \\
\text { 'life' }\end{array}$ & $\begin{array}{l}\text { a.sa.ga.O } \\
\text { 'morning glory' }\end{array}$ & $\begin{array}{l}\text { ha.ru.ya.su.MI } \\
\text { 'spring break' }\end{array}$ \\
\hline & & $\begin{array}{l}\text { a.me-GA } \\
\text { 'rain-NOM' }\end{array}$ & $\begin{array}{l}\text { i.no.ti-GA } \\
\text { 'life-NOM' }\end{array}$ & $\begin{array}{l}\text { a.sa.ga.o-GA } \\
\text { 'morning glory-NOM' }\end{array}$ \\
\hline & & & $\begin{array}{l}\text { a.me-ka.RA } \\
\text { 'rain-from' }\end{array}$ & $\begin{array}{l}\text { i.no.ti-ka.RA } \\
\text { 'life-from' }\end{array}$ \\
\hline
\end{tabular}

(3) Tonal patterns of Koshikijima Japanese

\begin{tabular}{|c|c|c|c|c|}
\hline Number of TBU & 2 & 3 & 4 & 5 \\
\hline \multirow[t]{3}{*}{ Type A } & $\begin{array}{l}\text { A.me } \\
\text { 'candy' }\end{array}$ & $\begin{array}{l}\text { sa.KA.na } \\
\text { 'fish' }\end{array}$ & $\begin{array}{l}\text { KE.da.MO.no } \\
\text { 'wild animal' }\end{array}$ & $\begin{array}{l}\text { NA.TU.ya.SU.mi } \\
\text { 'summer break' }\end{array}$ \\
\hline & & $\begin{array}{l}\text { a.ME-ga } \\
\text { 'candy-NOM' }\end{array}$ & $\begin{array}{l}\text { SA.ka.NA-ga } \\
\text { 'fish-NOM' }\end{array}$ & $\begin{array}{l}\text { KE.DA.mo.NO-ga } \\
\text { 'wild animal-NOM' }\end{array}$ \\
\hline & & & $\begin{array}{l}\text { A.me-KA.ra } \\
\text { 'candy-from' }\end{array}$ & $\begin{array}{l}\text { SA.KA.na-KA.ra } \\
\text { 'fish-from' }\end{array}$ \\
\hline \multirow[t]{3}{*}{ Type B } & $\begin{array}{l}\text { a.ME } \\
\text { 'rain' }\end{array}$ & $\begin{array}{l}\text { I.no.TI } \\
\text { 'life' }\end{array}$ & $\begin{array}{l}\text { A.SA.ga.O } \\
\text { 'morning glory' }\end{array}$ & $\begin{array}{l}\text { HA.RU.YA.su.MI } \\
\text { 'spring break' }\end{array}$ \\
\hline & & $\begin{array}{l}\text { A.me-GA } \\
\text { 'rain-NOM' }\end{array}$ & $\begin{array}{l}\text { I.NO.ti-GA } \\
\text { 'life-NOM' }\end{array}$ & $\begin{array}{l}\text { A.SA.GA.o-GA } \\
\text { 'morning glory-NOM' }\end{array}$ \\
\hline & & & $\begin{array}{l}\text { A.ME-ka.RA } \\
\text { 'rain-from' }\end{array}$ & $\begin{array}{l}\text { I.NO.TI-ka.RA } \\
\text { 'life-from' }\end{array}$ \\
\hline
\end{tabular}

The examples in (2) and (3) reveal interesting characteristics of $n$-pattern systems. First of all, in most of the $n$-pattern dialects, the prosodic unit is not a word, but a phrase. For example, the tonal pattern of /a.ME-ga/ 'candy-NOM', where a disyllabic noun is followed by a nominative case marker, is exactly the same with that of a trisyllabic noun, /sa.KA.na/ 'fish'. Also, the tonal patterns are remarkably systematic. Regardless of the internal structure of a prosodic phrase, its tonal pattern is decided by the number of TBUs. For instance, in (2), a disyllabic noun followed by a disyllabic particle, /a.me-KA.ra/ 'candy-from', has the same tonal pattern with a trisyllabic noun followed by a monosyllabic particle, /sa.ka.NA-ga/ 'fish-NOM', and also with a four-syllable noun, /ke.da.MO.no/ 'wild animal'. This observation is even true for compound nouns. In these dialects, the tonal pattern of a compound noun is determined by the tonal type of its first member (Hirayama, 1960). For example, /na.tu.ya.SU.mi/ or /NA.TU.ya.SU.mi/ 'summer break' is different from /ha.ru.ya.su.MI/ or /HA.RU.YA.su.MI/ 'spring break' even though they share the same noun, /ya.su.MI/ (or /YA.su.MI/) 'break' (Type B), as their second member. This difference results from the different tonal types of the first members, /NA.tu/ 'summer' (Type A) and /ha.RU/ 'spring' (Type B). 


\section{Previous approaches}

2.1 Kubozono (2012) Kubozono (2012) takes an autosegmental approach in explaining the tonal patterns of Kagoshima and Koshikijima Japanese. For Kagoshima Japanese, he proposes that Type A has a LHL tonal melody and Type B has a LH melody as their tonal representations and the tonal patterns of each type are derived from how the melodies are linked to TBUs. His analysis is provided in (4) and (5).

(4)

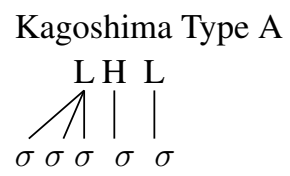

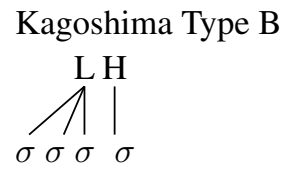

He states that the difference between Type A and Type B is whether the final syllable has a $\mathrm{H}$ tone (Type B) or not (Type A). The tonal melodies are linked to each TBU from right to left. For Type A, the final L tone is linked to the final syllable, and the $\mathrm{H}$ tone is linked to a penultimate syllable. The first $\mathrm{L}$ tone is linked to the antepenultimate syllable, and if there are remaining syllables, the first $\mathrm{L}$ tone spreads over them. For Type $\mathrm{B}$, the $\mathrm{H}$ tone is associated with the final syllable, and the $\mathrm{L}$ tone is linked to the penultimate syllable. The first $\mathrm{L}$ tone spreads over remaining syllables. He takes a similar approach to the Koshikijima dialect. The only difference is that Koshikijima Japanese has one more $\mathrm{H}$ tone in its tonal melody.

While his analysis generally works for long words, it cannot explain the tonal pattern in monomoraic words. Unexpectedly, Type A words show HL for Kagoshima and H for Koshikijima Japanese.

(6) Monomoraic words in Kagoshima and Koshikijima Japanese

\begin{tabular}{llll} 
& \multicolumn{2}{l}{ Kagoshima } & \multicolumn{2}{l}{ Koshikijima } \\
Type A & KAa(UR: ka) 'mosquito' & HI 'fire' \\
Type B & TE & 'hand' & HI
\end{tabular}

Since Kubozono assumes the directionality is right to left, the expected tonal pattern of monomoraic words in Type A would be L for both Kagoshima and Koshikijima Japanese. However, the actual output is HL in Kagoshima and $\mathrm{H}$ in Koshikijima Japanese. Also, note that monomoraic Type A words are lengthened in Kagoshima Japanese (Uwano, 2007). Kubozono states that monomoraic words show unexpected patterns in these dialects and the type distinction is preserved in Kagoshima but neutralized in Koshikijima Japanese.

2.2 Breteler (2013) Breteler (2013) takes an OT approach in explaining seven Japanese dialects with $n$-pattern systems. He assumes different intonational (tonal) types have different tonal melodies, and explains how the underlying melodies are realized in the output. Tableaux 1 and 2 show his analysis of the Kagoshima dialect.

\begin{tabular}{|ll||c|c|}
\hline \multicolumn{2}{|c|}{ Input: /hana + kara/ } & SYL-TO-TONE & SPREAD-LEFT \\
\hline \hline a. & ha.na-KA.ra & & \\
\hline b. & ha.NA-ka.ra & & $* !$ \\
\hline c. & ha.NA-KA.ra & & $* !$ \\
\hline
\end{tabular}

Tableau 1: Kagoshima word-level derivation for Type A. Input tonal melody: LHL (Breteler, 2013; p.33)

\begin{tabular}{|ll||c|c|}
\hline \multicolumn{2}{|c||}{ Input: /hana + bakkai/ } & SYL-TO-TONE & SPREAD-LEFT \\
\hline \hline a. & ha.na.bak.KAI & & $*$ \\
\hline b. & ha.na.bak.kaI & $* !$ & \\
\hline c. & ha.NA.BAK.KAI & & $* * ! * *$ \\
\hline d. & ha.na.BAK.KAI & & $* * ! *$ \\
\hline e. & ha.na.baK.KAI & $* !$ & $* *$ \\
\hline
\end{tabular}

Tableau 2: Kagoshima word-level derivation for Type B. Input tonal melody: LH (Breteler, 2013; p.34) 
In his analysis, SYL-To-TONE prevents the association of multiple tones to a single syllable, and SPREAD-LEFT states that the leftmost tone of a tonal melody spreads. In Tableau 1, candidates (b) and (c) are ruled out because of their violation of SPREAD-LEFT. In candidate (b), the rightmost L tone spreads over two syllables, and in candidate (c), the middle $\mathrm{H}$ tone spreads over two syllables. In Tableau 2, candidate (a) is the winning form, which violates SPREAD-LEFT once to satisfy a high-ranked constraint, SYL-TO-TONE. Candidate (b) does not violate SPREAD-LEFT, but it is eliminated because the final syllable has a rising tone. The other candidates cannot be the winning forms, because they violate SPREAD-LEFT multiple times.

While Breteler's analysis captures sentence-level variations by adopting Stratal OT, there are unclear points. First of all, he does not explain where the input melodies come from in his analysis. Since the tonal patterns are not lexical-specific information, the information on tonal patterns cannot be in the lexicon. Even if the tonal melodies were stored with each vocabulary item, the information would be unnecessarily redundant. Also, he assumes that the tonal melodies are provided in the input from the beginning, not seriously concerning about the richness of the base. Why should an input melody be LH or LHL for Kagoshima Japanese? How does his analysis prevent Kagoshima Japanese from having HL, HLH, or HLHL as its underlying tonal melodies? These questions remain unanswered. Finally, his analysis does not capture the generalization that the two tonal types are different only in one single tone. Kubozono (2011) suggests that the last TBU of Type A in both Kagoshima and Koshikijima Japanese seems to be extrametrical. However, in Breteler's analysis, the tonal melodies are assumed from the beginning, so it is difficult to explain that the two tonal types are similar in a systematic way but differ only in a single tone.

\section{Proposal}

The present paper provides an analysis that does not assume underlying tonal melodies. In this analysis, I approach these dialects through accent, which has long been used in the traditional Japanese phonology. In the present paper, I define an accent as an abstract prominence that is not necessarily involved with specific phonetic features. A major assumption is that every prosodic phrase in these dialects must have an accent. I also presume that the only information needed by native speakers is a word's tonal type. Since this information is purely arbitrary, it should be stored in the lexicon when children acquire vocabulary items. On the other hand, observations on these dialects suggest that the surface tonal pattern of every word or phrase does not need to be memorized. First of all, the tonal patterns in these dialects are remarkably systematic. Speakers can predict the tonal pattern of a word if they know which tonal type it belongs to. Furthermore, the tonal patterns of compound nouns, conjugational forms of verbs and adjectives, and their derivational forms are all predictable once the information on the tonal type is given. These suggest that the surface tonal patterns must be generated by the grammar, rather than memorized. In the framework of OT, it means that the information on surface tonal patterns is not present in the input. A set of constraints regulates the intonational system, and a candidate with an optimal tonal pattern is selected by a given ranking of constraints. Therefore, in the present analysis, I argue that the tonal patterns are entirely generated by the grammar.

The main proposal in this paper is that an accent needs to be right-aligned within each prosodic phrase, and the accent attracts a H tone. ${ }^{2}$ Also, adopting Kubozono's assumption (2011) that the last TBU of Type A is extrametrical, I propose that the final TBU of Type A is invisible in tone assignment so that a $\mathrm{H}$ tone is not linked to the TBU. ${ }^{3}$ The followings are constraints used in this paper:

- Nonfinality $(\mathrm{H})$ : A final TBU is not linked to a $\mathrm{H}$ tone.

- ACCEnt: A prosodic unit has an accent.

- AcCent/H: An accented TBU is linked to a H tone.

- Align-AcCEnt-R: Assign one violation for each TBU that intervenes between the right edge of a prosodic unit and the accented TBU.

- SPECIFy(T): Assign one violation for each TBU that is not linked to a tone.

- *H: Assign one violation for each TBU that is linked to a $\mathrm{H}$ tone.

- *RISE: Assign one violation for every syllable that has a rising tone.

2 This paper adopts de Lacy (2002) in that a prosodically prominent position attracts a $\mathrm{H}$ tone.

3 I assume Kagoshima and Koshikijima Japanese have a privative $\mathrm{H}$ vs. $\varnothing$ system, not H vs. L, and L tones are the default realization of $\varnothing$. See 5.2 (Makurazaki Japanese) for a different tone system. 
- *FALL: Assign one violation for every syllable that has a falling tone.

- StRong-AcCEnT: A tone linked to the accented TBU is not lined with other TBUs. (' $\mathrm{x}=$ accented) ex) $* \mathrm{H}$<smiles>C1[Al][Al]1</smiles>

- $\mathrm{OCP}(\mathrm{H})$ : Assign one violation for every two adjacent TBUs that are linked to two independent $\mathrm{H}$ tones. ex) $* \mathrm{H} \mathrm{H}$<smiles></smiles>

$\mathrm{x} \mathrm{x}$

\section{Analysis}

4.1 Kagoshima Japanese The present paper explains the difference between Type A and Type B in Kagoshima Japanese with an indexed constraint, $\operatorname{NONFINALITY}(H)^{\mathrm{A}}$, which affects only Type A words. ${ }^{4}$ Tableaux 3 and 4 show how the constraint works to select correct outputs for both types. (An accented TBU is indicated with a stress mark ['].) In Kagoshima Japanese, an accented TBU needs to be right-aligned and $\mathrm{H}$-toned. However, since the rightmost TBU of a Type A word is invisible in tone assignment, the final TBU cannot be H-toned, even though an accent falls on it. Thus, candidate (b), where the final TBU is accented and H-toned, is not an optimal candidate. Also, candidate (c), where an accented TBU is not H-toned, and candidate (d), which has no accent, are ruled out. Thus, candidate (a), where the penultimate TBU is H-toned and accented, wins. Unlike Type A, the final TBU of Type B is not invisible, so candidate (a), where the rightmost TBU is accented and $\mathrm{H}$-toned, is selected as the optimal output in Tableau 4.

\begin{tabular}{|lc||c|c|c|c|}
\hline \multicolumn{2}{|c|}{ Input: $/$ ame/ } & ACCENT & AC/H & NONFIN $^{\mathrm{A}}$ & ALIGN-AC-R \\
\hline \hline a. & 'A.me & & & & $*$ \\
\hline b. & a.'ME & & & $* !$ & \\
\hline c. & a.'me & & $* !$ & & \\
\hline d. & a.me & $* !$ & & & \\
\hline
\end{tabular}

Tableau 3: Kagoshima Type A word /A.me/ 'candy'

\begin{tabular}{|lc||c|c|c|c|}
\hline \multicolumn{2}{|c|}{ Input: /ame/ } & ACCENT & AC/H & NONFIN $^{\mathrm{A}}$ & ALIGN-AC-R $^{-1}$ \\
\hline \hline a. & a.'ME & & & - & \\
\hline b. & 'A.me & & & - & $* !$ \\
\hline c. & a.'me & & $* !$ & - & \\
\hline d. & a.me & $* !$ & & - & \\
\hline
\end{tabular}

Tableau 4: Kagoshima Type B word /a.ME/ 'rain'

Tableaux 5 and 6 illustrate how the analysis extends to longer words in Kagoshima Japanese. In Tableau 5, where the input is a Type A word, candidate (a) is ruled out because the final TBU is H-toned. However, an accent still needs to be as close to the right edge as possible, so candidate (b), where the penultimate TBU is $\mathrm{H}$-toned and accented, wins because of its minimal violation of ALIGN-ACCENT-R. Candidate (c), which violates ALIGN-ACCENT-R twice, and candidate (e), which has one more $\mathrm{H}$-toned TBU than candidate (a), are all suboptimal. Lastly, candidate (d), which has two adjacent $\mathrm{H}$-toned TBUs, is ruled out for its violation of STRONG-ACCENT, since the $\mathrm{H}$ tone linked to the accented TBU, /'MO/, is also linked to an unaccented one, /DA/. ${ }^{5}$ In contrast, since the final TBU of Type B is not subject to NonFinality $(\mathrm{H})^{\mathrm{A}}$, candidate (a), which does not violate any of the high-ranked constraints, is selected as the optimal output in Tableau 6. Candidate (b), which would be the optimal output for Type A, is ruled out for its violation of ALIGNACCENT-R. Also, candidate (d), which does not violate any of the high-ranked constraints, has one more

4 See Pater (2010) for constraint indexation.

5 Unless noted, two or more adjacent $\mathrm{H}$-toned TBUs are assumed to be linked to a single $\mathrm{H}$ tone throughout the paper. If /DA.' $\mathrm{MO}$ / were linked to two independent $\mathrm{H}$ tones, it would violate a high-ranked constraint, $\mathrm{OCP}(\mathrm{H})$, and would be eventually ruled out. 
H-toned TBU than candidate (a), so it is suboptimal. Candidate (e) critically violates STRONG-ACCENT, because it has the accented TBU and the penultimate TBU linked together to a single $\mathrm{H}$ tone.

\begin{tabular}{|c|c|c|c|c|c|c|c|c|}
\hline \multicolumn{2}{|c|}{ Input: /kedamono/A } & $\mathrm{ACNT} \perp \mathrm{AC} / \mathrm{H}$ & $\begin{array}{l}\text { NON- } \\
\text { FIN }^{\mathrm{A}}\end{array}$ & $\begin{array}{c}\mathrm{OCP} \\
(\mathrm{H})\end{array}$ & $\begin{array}{l}\text { ALIGN } \\
- \text { AC-R }\end{array}$ & $\begin{array}{l}\text { STRONG } \\
\text {-ACNT }\end{array}$ & $* \mathrm{H}$ & $\begin{array}{l}\text { SPECIFY } \\
(\mathrm{T})\end{array}$ \\
\hline a. & ke.da.mo.'NO & 1 & $* !$ & & & & $*$ & $* * *$ \\
\hline b. $\quad$ 땅 & ke.da.'MO.no & I & & 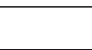 & $*$ & & $*$ & $* * *$ \\
\hline c. & ke.'DA.mo.no & 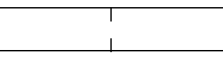 & & 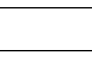 & $* * !$ & & $*$ & $* * *$ \\
\hline d. & ke.DA.'MO.no & I & & 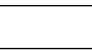 & $*$ & $* !$ & $* *$ & $* *$ \\
\hline e. & KE.da.'MO.no & $!$ & & 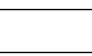 & $*$ & & $* * !$ & $* *$ \\
\hline
\end{tabular}

Tableau 5: Kagoshima Type A word /ke.da.MO.no/ 'wild animal'

\begin{tabular}{|c|c|c|c|c|c|c|c|c|}
\hline \multicolumn{2}{|c|}{ Input: /niwatori/ } & $\mathrm{ACNT} \quad \mathrm{AC} / \mathrm{H}$ & $\begin{array}{l}\text { NON- } \\
\text { FIN }^{\mathrm{A}}\end{array}$ & $\begin{array}{c}\mathrm{OCP} \\
(\mathrm{H})\end{array}$ & $\begin{array}{l}\text { ALIGN } \\
- \text { AC-R }\end{array}$ & $\begin{array}{c}\text { STRONG } \\
\text {-ACNT }\end{array}$ & $*^{H}$ & $\begin{array}{l}\text { SPECIFY } \\
(\mathrm{T})\end{array}$ \\
\hline a. & ni.wa.to.'RI & 1 & - & & & & $*$ & *** \\
\hline b. & ni.wa.'TO.ri & 1 & - & & $* !$ & & * & $* * *$ \\
\hline c. & ni.'WA.to.ri & 1 & - & & $* ! *$ & & * & $* * *$ \\
\hline d. & NI.wa.to.'RI & 1 & - & & & & $* * !$ & $* *$ \\
\hline e. & ni.wa.TO.'RI & 1 & - & & & $* !$ & $* *$ & $* *$ \\
\hline
\end{tabular}

Tableau 6: Kagoshima Type B word /ni.wa.to.RI/ 'chicken'

4.2 Koshikijima Japanese NonFinality $(\mathrm{H})^{\mathrm{A}}$ also plays an important role in Koshikijima Japanese. The difference is that SPECIFY(T) is higher ranked than $* \mathrm{H}$ in this dialect, so there are more $\mathrm{H}$-toned TBUs than in Kagoshima Japanese. (The reason for the different ranking of STRONG-ACCENT in this dialect is discussed in 4.4.) The main points are that an accented TBU is linked to an independent $\mathrm{H}$ tone and the $\mathrm{H}$ tone does not link to other TBUs. That is, there is a strong link between a $\mathrm{H}$ tone and an accented TBU. A pre-accent position is not $\mathrm{H}$-toned so that neither $\mathrm{OCP}(\mathrm{H})$ nor STRONG-ACCENT is violated. Tableaux 7 (Type A) and 8 (Type B) explain this point. In Tableau 7, candidate (a) has an accent and a $\mathrm{H}$ tone on the final TBU, and NonFinality $(\mathrm{H})^{\mathrm{A}}$ correctly eliminates it. Candidate (d), which would be optimal for Kagoshima Type A, is not selected due to its multiple violations of SPECIFY(T). Candidate (c) violates either $\mathrm{OCP}(\mathrm{H})$ (if two independent $\mathrm{H}$ tones are linked to /DA/ and /'MO/ respectively) or STRONG-ACCENT (if one $\mathrm{H}$ tone is linked to both /DA/ and /'MO/). Thus, candidate (b), which minimally violates ALIGN-ACCENT-R and $\operatorname{SPECIFY}(\mathrm{T})$, is selected.

\begin{tabular}{|c|c|c|c|c|c|c|c|c|}
\hline \multicolumn{2}{|c|}{ Input: /kedamono/A } & $\mathrm{ACNT} I \mathrm{AC} / \mathrm{H}$ & $\begin{array}{l}\text { NON- } \\
\text { FIN }^{\mathrm{A}}\end{array}$ & $\begin{array}{c}\mathrm{OCP} \\
(\mathrm{H})\end{array}$ & $\begin{array}{l}\text { STRONG } \\
\text {-ACNT }\end{array}$ & $\begin{array}{l}\text { ALIGI } \\
- \text { AC-F }\end{array}$ & $\begin{array}{l}\text { SPECIFY } \\
(\mathrm{T})\end{array}$ & $* \mathrm{H}$ \\
\hline a. & "KE.DA.mo.'NO & 1 & $* !$ & 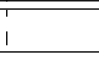 & 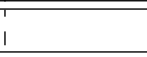 & & * & **** \\
\hline b. & KE.da.'MO.no & 1 & & 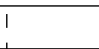 & 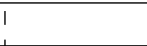 & * & ** & ** \\
\hline c. & ke.DA.'MO.no & 1 & & 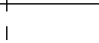 & $* !$ & & $* *$ & $* *$ \\
\hline d. & ke.da.'MO.no & 1 & & 1 & 1 & * & $* * ! *$ & * \\
\hline
\end{tabular}

Tableau 7: Koshikijima Type A word /KE.da.MO.no/ 'wild animal'

\begin{tabular}{|ll||c:c|c:c:c|c|c|c|}
\hline & Input: /niwatori/ & ACNT & AC/H & $\begin{array}{c}\text { NON- } \\
\text { FIN }^{\mathrm{A}}\end{array}$ & $\begin{array}{c}\text { OCP } \\
(\mathrm{H})\end{array}$ & $\begin{array}{c}\text { STRONG } \\
\text {-ACNT }\end{array}$ & $\begin{array}{c}\text { ALIGN } \\
\text {-AC-R }\end{array}$ & $\begin{array}{c}\text { SPECIFY } \\
(\mathrm{T})\end{array}$ & $* \mathrm{H}$ \\
\hline \hline a. & NI.WA.to.'RI & & - & & & & $*$ & $* * *$ \\
\hline b. & NI.wa.'TO.ri & & - & & & $* !$ & $* *$ & $* *$ \\
\hline c. & NI.WA.TO.'RI & & - & & $* !$ & & & $* * * *$ \\
\hline d. & NI.wa.to.'RI & & & - & & & & $* * !$ & $* *$ \\
\hline
\end{tabular}

Tableau 8: Koshikijima Type B word /NI.WA.to.RI/ 'chicken'

On the other hand, NonFinality $(\mathrm{H})^{\mathrm{A}}$ does not affect Type B words. Thus, candidate (a), which has the final TBU accented and minimally violates $\operatorname{SPECIFY}(\mathrm{T})$, wins out in Tableau 8. The accented TBU is 
not right-aligned in candidate (b), and candidate (c) violates STRONG-ACCENT (or OCP(H)), since the preaccent position is also H-toned. Candidate (d) has one more L-toned TBU than candidate (a), so it is not optimal.

4.3 Monomoraic words Both Kagoshima and Koshikijima Japanese show unexpected patterns in monomoraic words. In Kagoshima Japanese, Type A words are lengthened (/ka/ 'mosquito' $\rightarrow / \mathrm{KAa} /$ ), while Type B words are not (/te/ 'hand' $\rightarrow / \mathrm{TE} /$ ). This contrasts with the Koshikijima dialect, where both Type A and Type B words are not lengthened, but H-toned (Type A: /ka/ 'mosquito' $\rightarrow / \mathrm{KA}$, Type $\mathrm{B}:$ /hi/ 'day' $\rightarrow / \mathrm{HI} /)^{6}{ }^{6}$ The current analysis explains these patterns with NonFinALITY $(\mathrm{H})^{\mathrm{A}}$ and DeP$\mathrm{IO}(\mu)$. I propose that Kagoshima Japanese differs from Koshikijima in that it allows inserting an additional mora in a monomoraic word to avoid a violation of $\operatorname{NonFinALITY}(\mathrm{H})^{\mathrm{A}}$. Since an accented TBU needs to be H-toned, but the final TBU of Type A is invisible in tone assigment, an additional mora is needed $\left(\operatorname{NonFinality}(\mathrm{H})^{\mathrm{A}} \gg\right.$ DeP-IO $(\mu)$ ). On the other hand, in Koshikijima Japanese, an insertion of a mora is not allowed, so a monomoraic word ends up having an accent and a $\mathrm{H}$ tone on the final TBU (DEP-IO $(\mu)$ $\left.\gg \operatorname{NonFinality}(\mathrm{H})^{\mathrm{A}}\right)$. Tableaux 9 and 10 show how this proposal correctly selects the optimal output for Kagoshima Japanese. (The constraints that have no effect on the selection are not shown for space reason.)

In Tableau 9, candidate (b) violates $\operatorname{NonFinALiTy}(\mathrm{H})^{\mathrm{A}}$ and candidate (c) violates $\mathrm{Ac} / \mathrm{H}$ because the accented TBU is not H-toned. Thus, candidate (a), where an additional mora is inserted as a last resort, is the optimal form. However, NonFinality $(\mathrm{H})^{\mathrm{A}}$ has no effect on a Type B word, so candidate (a), where the final TBU is accented and H-toned, is selected as the optimal output in Tableau 10.

\begin{tabular}{|lc||c|c|c|c|c|c|}
\hline \multicolumn{2}{|c|}{ Input: $/ \mathrm{ka} /{ }^{\mathrm{A}}$} & ACNT & AC/H & NONFIN $^{\mathrm{A}}$ & DEP-IO $(\mu)$ & ALIGN-AC-R & $* \mathrm{H}$ \\
\hline \hline a. & 'KAa & & & $*$ & $*$ & $*$ \\
\hline b. & 'KA & & & $* !$ & & & $*$ \\
\hline c. & 'ka & & $* !$ & & & & \\
\hline
\end{tabular}

Tableau 9: Kagoshima Type A word /KAa/ 'mosquito'

\begin{tabular}{|lc||c|c|c|c|c|c|}
\hline \multicolumn{2}{|c|}{ Input: /hi/ } & ACNT & AC/H & NONFIN $^{\mathrm{A}}$ & DEP-IO $(\mu)$ & ALIGN-AC-R & $* \mathrm{H}$ \\
\hline \hline a. & 'HI & & & - & & & $*$ \\
\hline b. & 'HIi & ' & - & $* !$ & $*$ & $*$ \\
\hline c. & 'hi & & $* !$ & - & & & \\
\hline
\end{tabular}

Tableau 10: Kagoshima Type B word /HI/ 'day'

On the other hand, DeP-IO $(\mu)$ is higher ranked than NonFinality $(\mathrm{H})^{\mathrm{A}}$ in Koshikijima Japanese, an additional mora is not inserted in Tableau 11. Also, there is no reason to insert one more mora for a Type B word. Therefore, both Type A and Type B monomoraic words show the same tonal pattern. (The constraints that have no effect on the selection are not shown for space reason.)

\begin{tabular}{|lc||c|c|c|c|c|c|}
\hline \multicolumn{2}{|c|}{ Input: $/ \mathrm{ka} /{ }^{\mathrm{A}}$} & DEP-IO $(\mu)$ & ACNT & AC/H & NONFIN $^{\mathrm{A}}$ & ALIGN-AC-R & SPECIFY(T) \\
\hline \hline a. & 'KA & & & & $*$ & & \\
\hline b. & 'KAa & $* !$ & & & & $*$ & $*$ \\
\hline c. & 'ka & & & $* !$ & & & $*$ \\
\hline
\end{tabular}

Tableau 11: Koshikijima Type A word /KA/ 'mosquito'

\begin{tabular}{|lc||c|c|c|c|c|c|}
\hline \multicolumn{2}{|c|}{ Input: /hi/ } & DEP-IO $(\mu)$ & ACNT & AC/H & NONFIN $^{\mathrm{A}}$ & ALIGN-AC-R & SPECIFY(T) \\
\hline \hline a. & 'HI & & & & - & & \\
\hline b. & 'HIi & $* !$ & & & - & $*$ & $*$ \\
\hline c. & 'hi & & & $* !$ & - & & $*$ \\
\hline
\end{tabular}

Tableau 12: Koshikijima Type B word /HI/ 'day'

6 In Kubozono's analysis (2012), the expected pattern of a monomoraic Type A word is just L-toned without lengthening in both dialects. 
4.4 Contour tones and TBU Kubozono (2012) argues that a TBU is a syllable in Kagoshima Japanese, whereas that of Koshikijima is both a mora and a syllable (a mixed-TBU system). His argument is based on the observation that they differ in treating contour tones. Kagoshima Japanese shows no rising tone, but a falling tone only in monosyllabic words of Type A. (See 4.3 for an example.) In Type A words with more than two morae, if the final syllable is heavy, the entire syllable is L-toned and the penultimate syllable is H-toned (*/wa.sin.TOn/ $\rightarrow$ /wa.SIN.ton/ 'Washington'). On the other hand, in Koshikijima Japanese, (7), a rising tone is not observed in Type A, and a falling tone is allowed, but disfavored, in both Type A and B.

(7) No rising in Type A: */raI.to/ $\rightarrow$ /RAi.to/ 'light' (Type B: /SEN.seI/ 'teacher')

Disfavor of falling: */WA.SIn.TOn/ $\rightarrow$ /WA.sin.TOn/ 'Washington' (Type A)

$* /$ SEN.SEi -GA/ $\rightarrow$ /SEN.sei -GA/ 'teacher-NOM' (Type B)

Contrary to Kubozono (2012), this paper proposes that a TBU is a mora in both dialects, but * RISE and *FALL interact with other constraints, resulting in the odd distributions of contour tones. In particular, I suggest that *FALL is lower-ranked than *RISE in both dialects (*RISE $\gg *$ FALL). A falling tone is observed in Type A words of both dialects, but a rising tone is only observed in Type B words of Koshikijima Japanese. Also, I explain the reason more contour tones are observed in Koshikijima Japanese than in Kagoshima is because both *RISE and *FALL are relatively low-ranked in the Koshikijima dialect. Tableaux 13 and 14 show how the current proposal works. (The constraints that have no effect on the selection are not shown.)

\begin{tabular}{|c|c|c|c|c|c|c|c|c|}
\hline \multicolumn{2}{|c|}{ Input: /wasinton/ ${ }^{\mathrm{A}}$} & ACNT & NONFIN $^{A}$ & *RISE & *FALL & ALIGN-AC-R & STRONG-AC & $* \mathrm{H}$ \\
\hline a. 诲 & wa.SI'N.ton & & & & & $* *$ & $*$ & $* *$ \\
\hline b. & wa.sin.to'N & & $* !$ & $*$ & & & & $*$ \\
\hline c. & wa.sin.'TOn & & & & $* !$ & $*$ & & * \\
\hline d. & wa.si'N.ton & & & $* !$ & & $* *$ & & * \\
\hline
\end{tabular}

Tableau 13: Kagoshima Type A word /wa.SIN.ton/ 'Washington'

\begin{tabular}{|c|c|c|c|c|c|c|c|c|}
\hline \multicolumn{2}{|c|}{ Input: /sensei/ } & ACNT & NONFIN $^{\mathrm{A}}$ & $*$ RISE & *FALL & ALIGN-AC-R & STRONG-AC & $*^{*} \mathrm{H}$ \\
\hline a. 眐 & sen.SE'I & & - & & & & * & $* *$ \\
\hline b. & sen.se'I & & - & & & & & * \\
\hline c. & sen.'SEi & & - & & $* !$ & $*$ & & $*$ \\
\hline
\end{tabular}

Tableau 14: Kagoshima Type B word /sen.SEI/ 'teacher'

In Tableau 13, candidate (b), which has the final TBU H-toned, is eliminated by NonFinality $(\mathrm{H})^{\mathrm{A}}$. Also, candidates (c) and (d) have a contour tone, and *RISE and *FALL successfully rule out those candidates. Thus, candidate (a), which does not have any contour tone, wins out. Similarly, in Tableau 14, candidates (b) and (c) are all ruled out because of *RISE and *FALL. Since NonFinality $(H)^{\mathrm{A}}$ is not effective on Type B words, candidate (a), where the final syllable is H-toned, is selected as the optimal output.

However, in Koshikijima Japanese, STRONG-ACCENT is higher-ranked than *RISE and *FALL, meaning it is better to have contour tones than to have the accented and unaccented TBUs linked to a single tone. This constraint ranking explains why Koshikijima Japanese show more contour tones than Kagoshima Japanese. A falling tone is observed only in Type A, when there is no other option, as illustrated in Tableau 15. In the tableau, STRONG-ACCENT prevents candidate (d), which would have been the optimal output for Kagoshima Japanese, from being selected as the optimal output. Also, candidate (b) is ruled out, because it has one rising tone. Therefore, candidate (a), where the antepenult mora is accented, is selected as a last resort. On the other hand, in Tableau 16 (Type B), candidate (b) is not selected because of a falling tone on /RAn/. Candidate (a), which has no contour tone, is the most harmonic output.

The final constraint rankings for both dialects are provided in (8).

(8) Kagoshima: ACNT, AC/H $\gg \operatorname{NONFIN}^{\mathrm{A}}, \mathrm{OCP}(\mathrm{H}),{ }^{*} \mathrm{RISE} \gg \operatorname{DEP}-\mathrm{IO}(\mu) \gg *$ FAll $\gg$ Align-AC-R $\gg$ STRONG-AC $\gg * H \gg \operatorname{SPECIFY}(\mathrm{T})$

Koshikijima: DEP-IO $(\mu) \gg$ ACNT, AC/H $\gg$ NONFIN $^{A}$, OCP, STRONG-AC $\gg *$ RISE $\gg$

ALIGN-AC-R $\gg *$ FALL $\gg \operatorname{SPECIFY}(\mathrm{T}) \gg * \mathrm{H}$ 


\begin{tabular}{|c|c|c|c|c|c|c|c|c|}
\hline Input: /raito/ ${ }^{\mathrm{A}}$ & $\operatorname{DEP}(\mu)$ & ACNT & NONFIN $^{A}$ & STR-AC & *RISE & ALIGN-R & *FALL & SPEC(T) \\
\hline a. & & & & & & $* *$ & * & $* *$ \\
\hline ra'I.to & & & & & $* !$ & * & & $* *$ \\
\hline rai.'TO & & & $* !$ & & & & & $* *$ \\
\hline RA'I.to & & & & $* !$ & & * & & $*$ \\
\hline
\end{tabular}

Tableau 15: Koshikijima Type A word /RAi.to/ 'light'

\begin{tabular}{|c|c|c|c|c|c|c|c|c|}
\hline Input: /oranda/ & $\operatorname{DEP}(\mu)$ & ACNT & NONFIN $^{\mathrm{A}}$ & STR-AC & $*$ RISE & ALIGN-R & *FALL & SPEC(T) \\
\hline a. O.ran.'DA & & & - & & & & & ** \\
\hline O.RAn.'DA & & & - & & & & $* !$ & $*$ \\
\hline O.raN.'DA & & & - & $* !$ & * & & & * \\
\hline
\end{tabular}

Tableau 16: Koshikijima Type B word /O.ran.DA/ 'Netherlands'

\section{Other 2-pattern dialects}

The current proposal works in explaining not only Kagoshima and Koshikijima Japanese but also other 2-pattern dialects, such as Wan (Kikaijima) Japanese and Makurazaki Japanese, all spoken in Kyushu.

5.1 Wan (Kikaijima) Japanese The tonal patterns of Wan Japanese are similar to those of Koshikijima. The only difference is that contour tones do not exhibit odd distributions. ${ }^{7}$

(9) Tonal patterns of Wan Japanese (Kubozono, 2011) ${ }^{8}$

Number of TBU 2

Type $\alpha \quad$ mi.DU 'water'

3

Type $\beta \quad$ U.mi 'sea' ha.TA.na 'sword' TIn.ZYOo 'ceiling'

For Wan Japanese, I propose a similar constraint ranking to Koshikijima with a minor modification to the ranking of *RISE and *FALL. Since contour tones freely occur, both of the constraints are low-ranked. Also, in this dialect, NonFinality $(\mathrm{H})$ is subject to Type $\beta$ words, not Type $\alpha$. The ranking of $\operatorname{DeP}-\operatorname{IO}(\mu)$ is not decided at this moment, since Kubozono (2011) does not report monomoraic words of this dialect. Examples are shown in Tableaux 17 and 18. (Low-ranked constraints that have no effect on the selection are not shown.) In Tableau 17, candidate (a), which has the final TBU accented and H-toned, is selected as the optimal candidate of Type $\alpha$, whereas in Tableau 18, candidate (a), where the penultimate TBU is accented, is the harmonic output for Type $\beta$.

(10) Wan Japanese: ACNT, AC/H $\gg$ NONFIN $^{\beta}$, OCP, STRONG-AC $\gg$ ALIGn-AC-R $\gg \operatorname{SPECIFy(T)~} \gg$ *H, *RISE, *FALL

\begin{tabular}{|c|c|c|c|c|c|c|}
\hline Input: /kannari/ & ACNT, $\mathrm{AC} / \mathrm{H}$ & NONFIN $^{\beta}$ & $\mathrm{OCP}(\mathrm{H})$ & STR-AC & ALIGN-AC-R & SPEC(T) \\
\hline a. KAN.na.'RI & 0 & - & 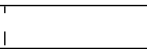 & & & * \\
\hline b. $\quad$ kan.'NA.ri & 1 & - & 1 & & $* !$ & $* * *$ \\
\hline c. kan.na.'RI & 1 & - & T & & & $* ! * *$ \\
\hline
\end{tabular}

Tableau 17: Wan Type $\alpha$ word /KAN.na.RI/ 'thunder'

\footnotetext{
7 In the field, the accent types of the Kikaijima dialect are called Type $\alpha$ and Type $\beta$, not Type A and B. This is because the vocabulary items in each group do not faithfully correspond to those of Type A and B in other 2-pattern dialects.

8 Type $\beta$ in the Wan dialect shows a variation between connective (sentence-medial) and non-connective (sentence-final) forms. The examples here show their non-connective forms.
} 


\begin{tabular}{|c|c|c|c|c|c|c|}
\hline Input: /tinzyoo/ ${ }^{\beta}$ & ACNT $\mathrm{AC} / \mathrm{H}$ & NONFIN $^{\beta}$ & $\mathrm{OCP}(\mathrm{H})$ & STR-AC & ALIGN-AC-R & SPEC(T) \\
\hline a. TIn.'ZYOo & 1 & & & & * & ** \\
\hline TIN.zyo'O & 1 & $* !$ & & & & * \\
\hline TIN.ZYO'O & 1 & & & $* !$ & & \\
\hline
\end{tabular}

Tableau 18: Wan Type $\beta$ word /TIn.ZYOo/ 'ceiling'

5.2 Makurazaki Japanese The last 2-pattern dialect considered in this paper is Makurazaki Japanese. An interesting point about this dialect is that it shows a $\mathrm{M}$ tone $(\bar{\sigma})$ at the final TBU of Type B words (Uwano, 2007). Consider the following examples:

(11) Tonal patterns of Makurazaki Japanese (Uwano, 2007)

Number of TBU 2

Type A

Type B ha NA 'nose'

HA.nā 'flower'
3

SA.ku.RA 'cherry blossom' YO.KO.i.TO 'weft'

O.TO.kō 'man'
4

A.SA.GA.ō 'morning glory'

Since this dialect shows a different characteristic (a M tone) from the other dialects, I assume that this dialect has both $\mathrm{H}$ and $\mathrm{L}$ tones specified, rather than a privative $\mathrm{H}$ vs. $\varnothing$, and a $\mathrm{M}$ tone is the default realization when a TBU is linked to neither a $\mathrm{H}$ tone nor a $\mathrm{L}$ tone. Additionally, the analysis uses ${ }^{*} \mathrm{~L}$, as $\mathrm{L}$ tones are also specified in this dialect, yet its ranking is relatively low. NonFinALiTy $(\mathrm{H})$ also plays a crucial role here, and it is only subject to Type B words. I propose that an accent must not be linked to a $\mathrm{L}$ tone $(* \mathrm{AC} / \mathrm{L})$ in this dialect, and a $\mathrm{H}$-toned accent is preferred if possible. Also, an accent must be right-aligned, which means that an accented TBU is always the final one even in Type B. NonFinALiTY $(\mathrm{H})^{\mathrm{B}}$ and $* \mathrm{AC} / \mathrm{L}$ are ranked higher than $\mathrm{AC} / \mathrm{H}$, making the accented TBU of a Type $\mathrm{B}$ word is neither L-toned nor $\mathrm{H}$-toned. This results in a $\mathrm{M}$ tone on the final TBU of a Type B word. Also, no contour tones are observed in this dialect, suggesting both *RISE and *FALL are undominated. (12) shows the constraint ranking the current analysis proposes, and example tableaux are provided below. (Three of the undominated constraints, *RISE, *FALL, and ACCENT, are not shown.)

(12) Makurazaki: ACnT, NonFin ${ }^{\mathrm{B}}, \mathrm{OCP}(\mathrm{H}),{ }^{*}$ Rise, *FAll, ALIGN-AC-R, *AC/L $\gg$ AC/H $\gg$ STRONG-AC $\gg * L \gg * H$

\begin{tabular}{|c|c|c|c|c|c|c|c|}
\hline Input: /sakura/ & NONFIN $^{B}$ & $\mathrm{OCP}(\mathrm{H})$ & STR-AC & ALIGN-R & $* \mathrm{AC} / \mathrm{L}$ & $\mathrm{AC} / \mathrm{H}$ & $* \mathrm{~L}$ \\
\hline a. SA.ku.'RA & - & 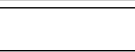 & & 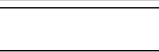 & & & $*$ \\
\hline sa.'KU.ra & - & 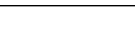 & 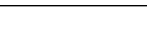 & $* !$ & & & $* *$ \\
\hline SA.KU.'rā & - & & 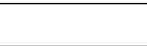 & 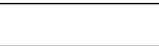 & & $* !$ & \\
\hline SA.KU.'ra & - & - & 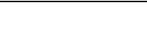 & 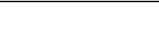 & $* !$ & * & * \\
\hline
\end{tabular}

Tableau 19: Makurazaki Type A word /SA.ku.RA/ 'cherry blossom'

\begin{tabular}{|c|c|c|c|c|c|c|c|}
\hline Input: /otoko/ ${ }^{\mathrm{B}}$ & NONFIN $^{B}$ & $\mathrm{OCP}(\mathrm{H})$ & STR-AC & ALIGN-R & $* \mathrm{AC} / \mathrm{L}$ & $\mathrm{AC} / \mathrm{H}$ & $* \mathrm{~L}$ \\
\hline a. O.TO.'kō & & & & & | & $*$ & \\
\hline o.'TO.ko & & & & $* !$ & । & & $* *$ \\
\hline O.to.'kō & & & & & | & $*$ & $* !$ \\
\hline O.to.' $\mathrm{KO}$ & $* !$ & & & & । & & * \\
\hline
\end{tabular}

Tableau 20: Makurazaki Type B word /O.TO.kō/ 'man'

In Tableau 19, since NonFinality $(\mathrm{H})^{\mathrm{B}}$ does not affect a Type A word, a final TBU can be accented and $\mathrm{H}$-toned. Therefore, candidate (a) wins over the other candidate. Candidate (c), which has the accented TBU M-toned, is ruled out by AC/H. In contrast, in Tableau 20, NONFInALITY $(H)^{B}$ is in effect, candidate 
(d), whose final TBU is accented and H-toned, is not selected. Also, candidate (b) is eliminated, because an accented TBU is not right-aligned. To avoid violations of NONFINALiTY $(H)^{\mathrm{B}}$, ALIGN-ACCENT- $\mathrm{R}$, and *AC/L, candidate (a), where the rightmost TBU is accented and M-toned, is selected as the optimal output.

\section{Conclusion}

This paper accounts for the tonal patterns of four Japanese dialects with 2-pattern accent systems. The difference in the tonal patterns of Type $\mathrm{A}$ (or $\alpha$ ) and $\mathrm{B}$ (or $\beta$ ) in these dialects is explained with an indexed constraint, NONFinaLiTY $(\mathrm{H})$, which makes it possible to provide a consistent account of the observed tonal patterns. The constraint rankings of all four dialects are provided below:

(13) Kagoshima: ACNT, AC/H $\gg \operatorname{NONFIN}^{\mathrm{A}}, \mathrm{OCP}(\mathrm{H}),{ }^{*} \mathrm{RISE} \gg \operatorname{DEP}-\mathrm{IO}(\mu) \gg *$ FALL $\gg$ Align-AC-R $\gg$ STRONG-AC $\gg * H \gg \operatorname{SPECIFY}(\mathrm{T})$

Koshikijima: DeP-IO $(\mu) \gg$ ACNT, AC/H $\gg$ NONFIN $^{A}$, OCP, STRONG-AC $\gg *$ RISE $\gg$

ALIGN-AC-R $\gg *$ FALL $\gg \operatorname{SPECIFY}(\mathrm{T}) \gg * \mathrm{H}$

Wan: ACNT, AC/H $\gg$ NONFIN $^{\beta}$, OCP, STRONG-AC $\gg \operatorname{ALIGN-AC-R~} \gg \operatorname{SPECIFY}(\mathrm{T}) \gg * \mathrm{H}$,

*RISE, *FALL

Makurazaki: ACNT, NONFIN ${ }^{\mathrm{B}}, \mathrm{OCP}(\mathrm{H}), *$ Rise, *FALl, Align-AC-R, *AC/L $\gg \mathrm{AC} / \mathrm{H} \gg$ STRONG-AC $\gg * L \gg * H$

The present proposal has several advantages. First of all, the difference between Type A and B is explained with a simple way, and the tonal patterns are entirely generated by the grammar. The only information needed by native speakers is a word's tonal type. The observation that tonal patterns are systematic and predictable is well captured in the present proposal, which suggests that it is on the right track. The indexed NonFinality $(\mathrm{H})$ accounts for the unexpected pattern in monomoraic words of both Kagoshima and Koshikijima Japanese without having any additional assumptions or constraints. In addition, this approach explains the unusual distributions of contour tones in both Kagoshima and Koshikijima Japanese, using *RISE and *FALL. This account also makes it possible to argue a TBU in these 2-pattern dialects is a mora, but the ranking of * RISE and that of *FALL are different from dialect to dialect. In Makurazaki, both constraints are undominated, not allowing any contour tones within a single syllable. In Wan Japanese, both are low-ranked so that contour tones freely occur in both types. In Kagoshima and Koshikijima Japanese, *RISE is higher-ranked than *FALL, allowing more falling tones than rising tones. Lastly, the current proposal uses the same constraints for all of the 2-pattern dialects with different rankings. Given that they are neighboring dialects, all spoken in Southwestern Kyushu, those micro-variations among these dialects should be explained with different rankings, not with different constraints, as the current proposal has done.

\section{References}

Breteler, Jeroen (2013). A Stratal OT Analysis of the Intonation of Japanese Diaclects with Multi Intonational Classes. Master's thesis, Utrecht University.

Hirayama, Teruo (1960). Zenkoku Akusento Jiten [Accent Dictionary of Japanese]. Tookyoodoo, Tokyo.

Kubozono, Haruo (2011). Kikaijima Nanbu, Chuubu chiiki-no akusento [The accent of Southern and Central Kikaijima]. General Study for Research and Conservation of Endangered Dialects in Japan: Research report on the Kikaijima Dialects, Natioanl Institute for Japanese Language and Linguistics, Tokyo, 51-70.

Kubozono, Haruo (2012). Kagoshima-ken Koshikijima hoogen no akusento [The accent of Koshikijima, Kagoshima Prefecture]. Onsei Kenkyuu 16:1, 93-104.

de Lacy, Paul (2002). The interaction of tone and stress in Optimality Theory. Phonology 19, 1-32.

Pater, Joe (2010). Morpheme-specific phonology: Constraint indexation and inconsistency resolution. Parker, Steve (ed.), Phonological Argumentation: Essays on Evidence and Motivation, Equinox, London, 123 - 154.

Uwano, Zendo (1999). Classification of Japanese accent systems. Kaji, Shigeki (ed.), Proceedings of the Symposium 'Cross-linguistic Studies on Tonal Phenomena, Tonogenesis, Typology and Related Topics', ILCAA, Tokyo, 151186.

Uwano, Zendo (2007). Two-pattern accent systems in three Japanese dialects. Tomas Riad, Carlos Gussenhoven (ed.), Tones and Tunes, vol.1: Typological studies in Word and Sentence Prosody, Mouton de Gruyter, Berlin, 147-165.

Uwano, Zendo (2012). Three types of accent kernels in Japanese. Lingua 122, 1415-1440. 